\title{
EFFECT OF PLANT MATERIALS ON DEVELOPMENTAL PERIODS OF TWO SPOTTED SPIDER MITE, TETRANYCHUS URTICAE KOCH (ACARI: TETRANYCHIDAE)
}

\author{
M T Islam, M M Haque*, N Naher and S Parween \\ Department of Zoology, Rajshahi University, Rajshahi-6205 Bangladesh
}

\begin{abstract}
Low concentration of raw flower juice of Calotropis porcera (Asclepiadecae) and seed dust of Nerium oleander (Apocynacae) significantly delayed the egg to adult development of two-spotted spider mite, Tetranychus urticae Koch, for three successive generations under laboratory trial. The flower juice of $C$. porcera was found more effective than the seed dust of $N$. oleander in delaying the developmental period of TSSM.
\end{abstract}

Keywords: C. porcera, N. oleander, T. urticae, TSSM, developmental period.

\section{Introduction}

The two-spotted spider mite (TSSM) is a detrimental pest infesting over 200 species of plants (Lienk et al. 1980), and distributed throughout the tropical and sub tropical parts of the world (Jeppson et al. 1975). A number of vegetable crops and ornamentals plants are known to attack by this mite in Bangladesh (Biswas et al. 2004). Infestation by spider mites may retard growth and adversely influence the quality of flower, seed or fruit production, defoliation, and various types of plants deformities, resulting in loss of crop yield (Biswas et al. 2004). Out breaks of TSSM infestation on lady's finger (Okra) and beans in Bangladesh has been reported by Gapud (1981).

Biological control programme of spider mites showed a varying degree of success (Helle and Sabelis 1985 $a, b)$, but the cost involvement for mass culture of the natural enemies, would not be economically viable for the farmers of Bangladesh. At presents the plant derived pesticides are attracting interests of the agriculture scientists, as these are environmentally safe and non-toxic to human. Neem-based pesticides have been reported to show adverse effects on development and reproduction of TSSM (Dimetry et al. 1993, Sundaram and Sloane 1995, Sanguanpong and Schmutterer 1992). In a recent study, Naher et al. (2006) reported that some indigenous plant materials of Bangladesh significantly retarded the development of immature stages of TSSM.

Intensive researches on the botanicals in controlling the populations of the spider mites are very much needed for safety of the environment and production of chemical free crops. The present experiment is an attempt to determine the potential of two indigenous plants, Calotropis porcera (Asclepiadecae) and Nerium oleander (Apocynacae), on the developmental time of the immature stages of Tetranychus urticae Koch in successive three generations, under laboratory condition.

\section{Materials and methods}

Adult $T$. urticae were collected from the laboratory population raised on potted bean plants in the department of Zoology, Rajshahi University. Five to six adult mites were reared on leaf disc $(2 \mathrm{~cm} \mathrm{diam}$.) of the host plant, in a glass petridish $(9 \mathrm{~cm}$ diam.). Under surface of the leaf disc was placed upward. Water soaked

\footnotetext{
${ }^{*}$ Corresponding author.
} 
cotton wool was placed under the leaf disc to keep the environment moist and the leaf fresh. The petridish covered with lid was then kept undisturbed at room temperature $\left(30 \pm 2^{\circ} \mathrm{C}\right)$ in the laboratory. The leaf disc was checked on two hourly basis for egg laying. The adults were removed following egg laying and kept in other petridish. The eggs were then allowed to develop into adults. The leaf discs were usually replaced with fresh ones after two days.

Raw flower juice of $C$. porcera and seed dust of $N$. oleander were used in the present experiment. Fresh flowers of $C$. porcera were collected from the wild plant. Fruits of $N$. oleander were collected from Rajshahi University campus. Flower of $C$. porcera was blended in an electric blender, and juice obtained was passed through fine cloth to collect the juice. Seeds from the fruits of $N$. oleander were removed with the help of a knife, cut in to thin slices and sun dried for 2-3 days. Seed dust was made by using an electric grinder. Stock solutions for both flower juice and seed dust were prepared, from which the experimental doses were made through serial dilution with distilled water. The stock solutions were kept in refrigerator, and fresh doses were prepared during the experiment.

Flower juice stock solution was prepared by adding $2 \mathrm{ml}$ of distilled water with $1 \mathrm{ml}$ of raw juice (2:1water and flower juice), and blended well. When $0.02 \mathrm{ml}$ of the stock solution was evenly spreaded over a leaf disc (2 $\mathrm{mm}$ diameter), the concentration obtained was $4629.63 \mathrm{nl} \mathrm{cm}^{-2}$. Then by adding 4,8 and $16 \mathrm{ml}$ of water to $0.02 \mathrm{ml}$ of the stock solution, the concentrations obtained were 2314.81, 1157.41 and $578.70 \mathrm{nl} \mathrm{cm}^{-2}$ respectively. The seed dust $(0.5 \mathrm{~g})$ was added to $10 \mathrm{ml}$ of distilled water and stirred well to dissolve for the preparation of stock solution. When $0.02 \mathrm{ml}$ of this solution was sprayed evenly on the leaf disc as mentioned, the concentration obtained was $694.44 \mathrm{ng} \mathrm{cm}^{-2}$. By mixing 20,40 and $80 \mathrm{ml}$ of distilled water to the stock solution, the concentrations obtained were $347.22,173.61$ and $86.81 \mathrm{ng} \mathrm{cm}^{-2}$ respectively.

Sets of 15 leaf discs were treated with each concentration of the experimental plant materials, separately, and placed on wet cotton wool in 15 petridishes. Adult females were allowed to oviposit on the leaf disc. After egg laying the females and excess eggs were removed from the petridish, keeping only one egg in each petridish. The petridishes were then covered with the lid, leaving a small gap to check excess evaporation. Another set of 15 untreated leaf discs were similarly infested with the mite's eggs, and used as control. Two separate control batches were kept for the two plant materials, as both the experiments could not run simultaneously.

Leaf discs of both treated and control batches were replaced with a treated and untreated fresh leaf disc respectively, after 3-4 days. Daily observation was made; time taken for each moulting up to adult emergence was recorded. Similar experiments were set using the eggs laid by 1st and 2nd generations of the mite, and the same data were collected throughout these three generations. The whole experiment was completed during May to September 2006 , when the average room temperature was $30 \pm 2^{\circ} \mathrm{C}$.

\section{Results and Discussion}

Embryonic developmental period: Both flower juice of $C$. porcera and seed dust of $N$. oleander significantly delayed embryonic development of TSSM within the eggs. Time for embryogenesis was increased with the increased concentrations of the plant materials, in all the three generations (Table 1). Flower juice of $C$. porcera was found to be significantly potent in retarding the rate of embryogenesis, compared to seed dust of N. oleander.

Larval period: Concentrations of flower juice of $C$. porcera increased the larval period successively in $1^{\text {st }}$ and $2^{\text {nd }}$ generations of TSSM. But higher concentration of seed dust did not lengthened the larval period. There were no significant differences of the potencies in between two plants materials on the larval period of TSSM. 
Table 1. Effect of plant materials on the developmental periods (day) of TSSM in three generations.

\begin{tabular}{|c|c|c|c|c|c|c|c|c|c|c|}
\hline \multirow{3}{*}{ Life stage } & \multicolumn{5}{|c|}{ C. porcera flower juice } & \multicolumn{5}{|c|}{$N$. oleander seed dust } \\
\hline & \multirow{2}{*}{$\begin{array}{l}\text { Concentration } \\
(\mathrm{nlcm}-2)\end{array}$} & \multicolumn{4}{|c|}{ Generation } & \multirow{2}{*}{$\begin{array}{l}\text { Concentration } \\
\quad\left(\mathrm{nlcm}^{-2)}\right.\end{array}$} & \multicolumn{4}{|c|}{ Generation } \\
\hline & & 1st & 2nd & 3rd & Mean & & $1 \mathrm{st}$ & 2nd & 3 rd & Mean \\
\hline \multirow{6}{*}{ Embryo } & 4629.63 & 2.84 & 3.65 & 2.92 & 3.14 & 694.44 & 2.50 & 2.50 & 2.39 & 2.46 \\
\hline & 2314.81 & 2.59 & 2.96 & 3.08 & 2.88 & 347.22 & 2.53 & 2.63 & 2.58 & 2.58 \\
\hline & 1157.41 & 2.38 & 3.31 & 2.50 & 2.73 & 173.61 & 2.09 & 2.08 & 2.00 & 2.06 \\
\hline & 578.70 & 2.09 & 2.77 & 2.93 & 2.60 & 86.81 & 1.69 & 1.71 & 1.88 & 1.75 \\
\hline & Control & 1.50 & 1.63 & 2.13 & 1.71 & Control & 1.59 & 1.50 & 1.80 & 1.64 \\
\hline & \multicolumn{10}{|c|}{$t=3.87^{*}, P<0.05$} \\
\hline \multirow{6}{*}{ Larva } & 4629.63 & 1.63 & 2.50 & 2.23 & 2.12 & 694.44 & 1.60 & 1.61 & 2.12 & 1.78 \\
\hline & 2314.81 & 1.50 & 1.88 & 2.21 & 1.86 & 347.22 & 1.56 & 1.40 & 1.88 & 1.61 \\
\hline & 1157.41 & 1.72 & 2.08 & 2.46 & 2.09 & 173.61 & 1.56 & 1.88 & 2.32 & 1.92 \\
\hline & 578.70 & 1.97 & 2.10 & 2.46 & 2.18 & 86.81 & 2.16 & 2.04 & 1.88 & 2.03 \\
\hline & Control & 1.16 & 1.63 & 2.50 & 1.76 & Control & 1.81 & 2.19 & 2.00 & 2.00 \\
\hline & \multicolumn{10}{|c|}{$\mathrm{T}=1.36$} \\
\hline \multirow{6}{*}{ Protonymph } & 4629.63 & 2.84 & 2.25 & 3.79 & 2.96 & 694.44 & 2.97 & 2.68 & 2.33 & 2.26 \\
\hline & 2314.81 & 2.25 & 2.77 & 3.17 & 2.73 & 347.22 & 2.56 & 2.47 & 2.36 & 2.78 \\
\hline & 1157.41 & 2.16 & 2.58 & 2.62 & 2.45 & 173.61 & 2.47 & 2.42 & 2.40 & 2.64 \\
\hline & 578.70 & 2.22 & 2.77 & 2.65 & 2.55 & 86.81 & 2.75 & 2.5 & 3.14 & 2.80 \\
\hline & Control & 2.13 & 2.41 & 2.63 & 2.39 & Control & 1.94 & 2.29 & 1.93 & 2.36 \\
\hline & \multicolumn{10}{|c|}{$t=1.22$} \\
\hline \multirow{6}{*}{ Deutonymph } & 4629.63 & 1.75 & 2.17 & 2.38 & 2.10 & 6994.44 & 1.93 & 2.43 & 2.23 & 2.20 \\
\hline & 2314.81 & 2.41 & 2.5 & 2.36 & 2.42 & 347.22 & 2.19 & 2.43 & 3.73 & 2.78 \\
\hline & 1157.41 & 2.56 & 2.58 & 2.82 & 2.65 & 173.61 & 2.47 & 2.75 & 2.70 & 2.64 \\
\hline & 578.70 & 1.94 & 2.46 & 2.46 & 2.29 & 86.81 & 2.6 & 2.88 & 2.91 & 2.80 \\
\hline & Control & 1.84 & 2.47 & 2.37 & 2.23 & Control & 2.47 & 2.39 & 2.21 & 2.36 \\
\hline & \multicolumn{10}{|c|}{$t=2.275$} \\
\hline \multirow{6}{*}{ Egg to Adult } & 4629.63 & 9.05 & 10.54 & 11.29 & 10.79 & 694.44 & 9.00 & 9.21 & 8.95 & 9.05 \\
\hline & 2314.81 & 8.38 & 10.08 & 11.00 & 9.42 & 347.22 & 8.84 & 8.93 & 10.50 & 9.42 \\
\hline & 1157.41 & 8.81 & 10.54 & 10.36 & 9.90 & 173.61 & 8.63 & 8.92 & 9.25 & 8.93 \\
\hline & 578.70 & 8.22 & 10.00 & 10.46 & 8.93 & 86.81 & 9.20 & 9.04 & 9.78 & 9.34 \\
\hline & Control & 6.72 & 8.19 & 9.67 & 8.19 & Control & 7.84 & 8.36 & 7.96 & 8.05 \\
\hline & \multicolumn{10}{|c|}{$t=2.73$} \\
\hline
\end{tabular}

Protonymphal period: Duration of the protonymphal stage increased with the increased concentration of flower juice of $C$. porcera in all generations. Whereas, all concentrations of seed dust of $N$. oleander similarly affected the protonymphal duration, and the affect was decreased in the following generations from the 1st generation of TSSM (Table 1).

Deutonymphal period: Deutonymphal period of the $T$. urticae was little affected by both of the plant materials, and showed similar affects throughout the three generations (Table 1).

Egg-adult developmental time: The egg to adult developmental time of TSSM varied among the generations when treated with $C$. porcera flower juice. The effect was increased from 1 st to 3 rd generations. However $N$. oleander seed dust similarly increased the total developmental time in three generations of TSSM in comparison to untreatment. Egg to adult duration increased with the increased concentration of flower juice (Table 1).

Temperature plays vital role in the growth and development of crop insects. The preferred temperature for rapid development of $T$. urticae population is $25-27^{\circ} \mathrm{C}$ (Naher et al. 2004). The egg - adult development of a female TSSM is completed in approximately 6.5 days at $30^{\circ} \mathrm{C}$ (Sabelis 1981); and males completed development earlier than females (Michell 1973). So, in the field, TSSM can produce quick succession of generations within a period when the temperature ranges from $25-30^{\circ} \mathrm{C}$. The population buildup of this mite species can be reduced by delaying their developmental period. 
In the present study, both flower juice and seed powder of two indigenous plant, showed equipotentiality in lengthening the egg-adult developmental period of TSSM in successive three generations. The average developmental periods in untreated population were $6.72,8.19$ and 9.67 days in $1 \mathrm{st}$ to 3 rd generations. The maximum developmental periods were recorded in highest concentration of $C$. porcera flower juice treated population were 9.05, 10.54 and 11.29 days in 1st, 2nd and 3rd generations respectively; and that for highest concentration of $N$. oleander seed dust were $9.00,9.21$ and 8.95 days in three generations.

Labanowska (1990) reported that spraying a number of chemical pesticides before bloom of strawberry satisfactorily controlled the population of TSSM. So, spraying of flower juice of $C$. porcera or sprinkling of seed dust $N$. oleander on bean plants may satisfactorily delay the development period of $T$. urticae, which ultimately will control their population without affecting the environment.

\section{References}

Biswas G C, Islam W, Haque M M, Saha R K, Hoque K M P, Islam M S and Haque M E (2004) Some biological aspects of carmine mite, Tetranychus cinnabarinus Boisd. (Acari: Tetranychidae) infesting egg-plant from Rajshahi. J. biosci. 4(5): 588-591.

Dimetry N Z, Amer S A A and Reda A S (1993) Biological activity of two neem seed kernel extracts against the twospotted spider mite Tetranychus urticae Koch. J. Appl. Ent. 116: 308-312.

Gapud V P (1981) Insect and mite pest of plant crops in Bangladesh and their natural enemies. In: A Compendium for biological control in IPM. United States Agency for International Development Agriculture Research Council/Chechi and Company Consulting Inc. 265pp.

Helle W and Sabelis M W [eds.] (1985a) Spider mites: Their biology, natural enemies and control. Volume 1 Part A. 406 pp. Elsevier, Amsterdam.

Helle W and Sabelis M W [eds.]. (1985b) Spider mites: Their biology, natural enemies and control. Volume 1 Part B. 458 pp Elsevier, Amsterdam.

Jeppson L F, Keifer H H and Baker E W (1975) Mites injurious to economic plants. 614pp. University of California Press, USA,

Labanowska B H (1990) Effectiveness of some new generation acaricides in the control of two-spotted spider mite (Tetranychus urticae Koch) on strawberries. Fruit Science Report (Poland) 17(3): 137-147.

Lienk S E, C M Walve and R W Weives (1980) Phytophagus and predator mite on apple in New York. Search Agriculture (Geneva N Y). No. 6.

Mitchell R (1973) Growth and population dynamics of a spider mite (Tetranychus urticae K., Acarina: Tetranychidae). Ecology 54: 1349-1355.

Naher N, Islam W, Khalequzzama M and Haque M M (2004) Abundance of two-spotted spider mite, Tetranychus urticae Koch (Acari: Tetranychidae) on bean. Univ. J. Zool. Rajshahi Univ. 23: 43-48.

Naher N, Islam T, Haque M M and Parween S (2006) Effects of native plants and IGRs on the development of Tetranychus urticae Koch (Acari: Tetranychidae). Univ.J. Zool. Rajshahi univ. 25: (19-22).

Sabelis M W (1981) Biological control of two-spotted spider mites using phytoseiid predators. Part 1. Modeling the predator-prey interaction at the individual level. Agricultural Research Reports No. 910. Wageningen, Netherlands.

Sanguanpong $\mathrm{U}$ and Schmutterer $\mathrm{H}$ (1992) Laboratory trials on the effects of neem oil and neem seed based extracts against the two spotted spider mite Tetranychus urticae Koch (Acari: Tetranychidae). Zeischrift fur Pflanzenkrankheiten und Pflanzenschutz 99(6): 637-646.

Sundaram K M S and Sloane L (1995) Effects of pure and formulated azadirachtin, a neem based biopesticide, on the phytophagous spider mite, Tetranychus urticae Koch. J. Environ. Sci. Health B 30 (6): 801-814. 